\title{
REMETENTE EM METAMORFOSE: JoAN POnÇ NO TURBILHÃO CULTURAL BRASILEIRO
}

SeNDER IN METAMORPHOSIS: JoAN PONÇ IN THE BRAZILIAN CULTURAL WHIRLWIND

\author{
Margareth dos Santos \\ Universidade de São Paulo \\ São Paulo, SP - Brasil \\ ORCID 0000-0001-9792-0353
}

\section{Resumo}

Este artigo tem como objetivo estudar a obra do pintor Joan Ponç, um dos renovadores das vanguardas artísticas da pós-guerra civil espanhola, durante sua estância no Brasil. Dos quase 10 anos no país, de 1953 a 1962, nos restringiremos ao período de 1956 a 1959, a fim pensar seus contatos, apropriaçóes e contençóes em solo brasileiro. Através dessa discussão, se pretende revelar algumas mudanças na pintura do cataláo como efeito de seu período em solo nacional e contribuir para que se reflita sobre sua importância nos anos 1950-1960 no Brasil e seu trânsito espacial e estético na cena artística brasileira.

Palavras-chave: Joan Ponç e o Brasil; Relaçôes Interartes; Vanguarda Brasileira e Espanhola.

\begin{abstract}
This article intends to discuss the period in which the painter Joan Ponç, one of the renovators of the artistic vanguards of the Spanish civil war in Brazil. Of the almost ten years in the country, from 1953 to 1962 , we will restrict ourselves to the period from 1956 to 1959 , to reflect on his contacts, appropriations and restraints in Brazilian lands. Through this discussion, we intend to reveal some changes in Catalan painting as an effect of its Brazilian period and contribute to reflect on its importance
\end{abstract}

\section{Resumen}

Este artículo tiene como objetivo estudiar la obra del pintor Joan Ponç, uno de los renovadores de las vanguardias artísticas de la posguerra civil espańola, durante su estancia en Brasil. De los casi diez años en el país, de 1953 a 1962, nos restringiremos al periodo de 1956 a 1959, para pensar sus contactos, apropiaciones y contenciones en tierras brasileñas. A través de esa discusión, se pretende revelar algunos cambios en la pintura del catalán a partir de su estancia en Brasil, además de contribuir 
in the 1950s and 1960s in Brazil and its spatial and aesthetic transit in the Brazilian art scene.

Keywords: Joan Ponç and Brazil; Interartist Relations; Brazilian and Spanish Vanguards. para que se reflexione más sobre su importancia en los años 1950-1960 en Brasil y en su tránsito espacial y estético en la escena artística brasileña.

Palabras clave: Joan Ponç y Brasil; Relaciones Interartísticas; Vanguardias Brasileña y Española.

Em 1956, três anos depois de ter deixado a Espanha para viver no Brasil, o pintor Joan Ponç, um dos renovadores das vanguardas artísticas no pós-guerra civil espanhola, estava totalmente inserido na vida cotidiana e cultural de São Paulo: em 1953 expusera na II Bienal de São Paulo, já localizada no Parque Ibirapuera, e, individualmente, no MAM (Museu de Arte Moderna de São Paulo), ainda sediado no centro de São Paulo, no edifício dos Diários Associados, na rua Sete de abril; vivera por um breve período em Ribeirão Pires (de 1954 a 1955), nessa pequena cidade a uma hora da capital por trem e que exibia uma grande área de Mata Atlântica pujante. Ali, teve uma produção intensa, apresentada em uma segunda individual no MAM e na mostra 50 anos de Paisagem Brasileira (1956) e, por fim, colaborara com os artistas Lívio Abramo e Flávio de Carvalho nos espetáculos de dança da coreógrafa polonesa Yanka Rudzka (1956).

Em meio a esses trânsitos geográficos e artísticos, passou a viver na Bela Vista no final de 1956, mais especificamente, na Rua Eugênio de Lima (hoje Joaquim Eugênio de Lima), numa casa pequena. Ali, começa a rumiar a ideia de montar um ateliê/escola, como uma maneira de dar a conhecer suas ideias sobre a arte e uma forma de esquivar-se dos assédios de marchands e de colecionadores particulares.

Me dedico a la enseñanza, como medio más apropiado para mantener mi libertad creadora, al margen de marchands, galerias y otras calamidades, que verifico van destruyendo paulatinamente incluso a los más resistentes (PONÇ, 2009, p. 187). 
A partir dessa ideia, inicia seu percurso docente ao começar a dar aulas para Nelson Leirner. Segundo o artista brasileiro, as aulas ocorriam em seu pequeno estúdio, localizado na rua Veiga Filho, ali, depois de ter suas primeiras aulas de arte, os dois partiam para o restaurante japonês da Dona Beth, localizado nas proximidades do estúdio, onde conversavam, sobretudo, sobre amenidades, num convívio bastante mundano.

Apesar de Ponç vislumbrar a capacidade criativa de Leirner e admirá-lo por suas opinióes artísticas, o período de aulas dura apenas alguns meses, pois segundo o artista brasileiro, o interesse pela tinta acrílica (difícil de encontrar no país naquele período) e outras formas de configuração artística o levam a distintas pesquisas e caminhos ${ }^{1}$.

No mesmo ano, Ponç encontra o imóvel "perfeito" (Figura 1) para a instalação de seu ateliê-escola, localizado na Rua dos Ingleses, 224, muito próximo à sua residência.
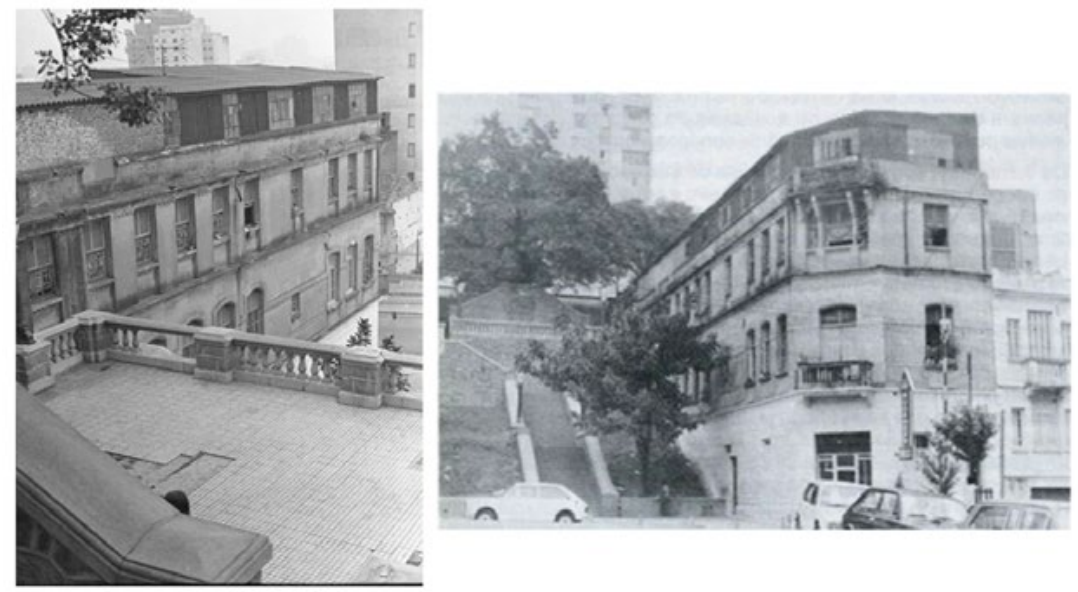

Figura 1: L'Espai. Vista da Rua dos Ingleses e da Rua Fortaleza, respectivamente. Fonte: (CArquivo da cidade de São Paulo. ${ }^{2}$

1 LEIRNER, N. Entrevista III. Entrevistadora: Margareth dos Santos. Rio de Janeiro, julho de 2017.

2 Agradeço ao Departamento dos Museus Municipais, da Secretaria Municipal de Cultura de São Paulo a cessão das imagens para o uso no artigo e acadêmico. 
O ateliê-escola situava-se no último andar do edifício, numa espécie de "barracáo" improvisado em alvenaria. Desde suas grandes janelas podia-se vislumbrar um horizonte amplo, posto que o emaranhado de edifícios altos ainda não havia tomado a região, concedendo a Ponç e a seus alunos uma vista privilegiada de uma cidade cinza, mas ainda salpicada de pontos verdes. Em sua maioria os alunos pertenciam à nata da colônia judaica de Sáo Paulo e, com eles, Ponç mergulhou profundamente nesse universo.

Embora o artista tivesse tido contato com algumas referências desse universo através da figura de Isai Leirner ${ }^{3}$ durante as Bienais de São Paulo e a convocatória do Prêmio Isai Leirner de Arte Contemporânea, é na relação professor-aluno que sua curiosidade e um autêntico interesse por essa cultura revela-se intenso e prolongado.

Me dedico a la enseñanza, como medio más apropiado para mantener mi libertad creadora, al margen de marchands, galerias y otras calamidades, que verifico van destruyendo paulatinamente incluso a los más resistentes. En la escuela, no hay distinción profesor-alumno; somos hermanos, soy un hermano que ha visitado un mágico lugar llamado creación y cuenta sus experiencias. Mi amor a los demás nunca fue tan intenso (PONÇ, 2009, p. 187).

Como resultado do convívio com seus alunos ${ }^{4}$, Ponç passa a estudar hebraico através de contatos com o Centro Cultural Brasil-Israel e se debruça sobre os mistérios da Cabala. Como um buscador de mistérios e experiências místicas, entendido como um recurso do sujeito para a compreensão de seu lugar no mundo e do que o cerca,

3 Isai Leirner (Varsóvia, Polônia, 1904 - São Paulo, SP, 1962). Industrial, colecionador e galerista, fixou-se em São Paulo em 1927 junto com sua esposa, a artista Felícia Leirner. De 1955 a 1957 integra a diretoria do MAM. Em 1957 rompe com o MAM por conta de uma polêmica relacionada à III Bienal de Sáo Paulo. Com a ruptura monta uma exposição paralela intitulada 12 artistas e institui o Prêmio Isai Leirner de Arte Contemporânea; com o sucesso da empreitada funda a Galeria de Artes das Folhas. Após a sua morte, no dia 13 de novembro de 1962, o prêmio Leirner acaba e, pouco depois, a galeria é fechada.

4 Gostaria de deixar registrado meu imenso agradecimento a Jeanete Musatti, Nelson Leirner, Paulina Rabinovich, Lygia Rabinovich, Kátia Rabinovich, Dora Leirner e Carlos Durán (Galería Senda) por toda atenção, depoimentos entusiasmados e pela cessão da correspondência com Ponç e das imagens das obras em poder dos mesmos, sem o apoio e contribuição dessas pessoas, dificilmente, esse estudo teria alcançado a densidade necessária. 
o pintor passa a frequentar sinagogas e submete-se a uma espécie de batismo, do qual emerge "Iohanan", sua nova identidade artística vinculada ao mundo hebraico.

O nome assumido, gráfica e animicamente, encontra-se, em grande parte, nas assinaturas da Suite Cabezas (1958-1959) e Cabezas Clássicas (1960-1962), esta última conhecida no Brasil como a Suite Filósofos, segundo depoimento de Jeanete Musatti ${ }^{5}$, artista plástica e ex-aluna de Ponç.

A Figura 2 repete algumas constantes na série ponciana: a cabeça inclinada, o olhar fixo no vazio, uma preocupação por delinear de forma acentuada a boca dos personagens pintados e a presença de chapéus pontiagudos, denominados "cucuruchos" por Ponç. Essas cabeças repetem-se em gesto ancestral, que por sua vez, vincula-se a inúmeras possibilidades e embaralha-se em suas referências: a boca entreaberta como um portal, pronta para receber o sopro da vida, que caracteriza a incorporação, o chapéu icônico como uma forma de verticalização ou ascensão em busca do toque da divindade.

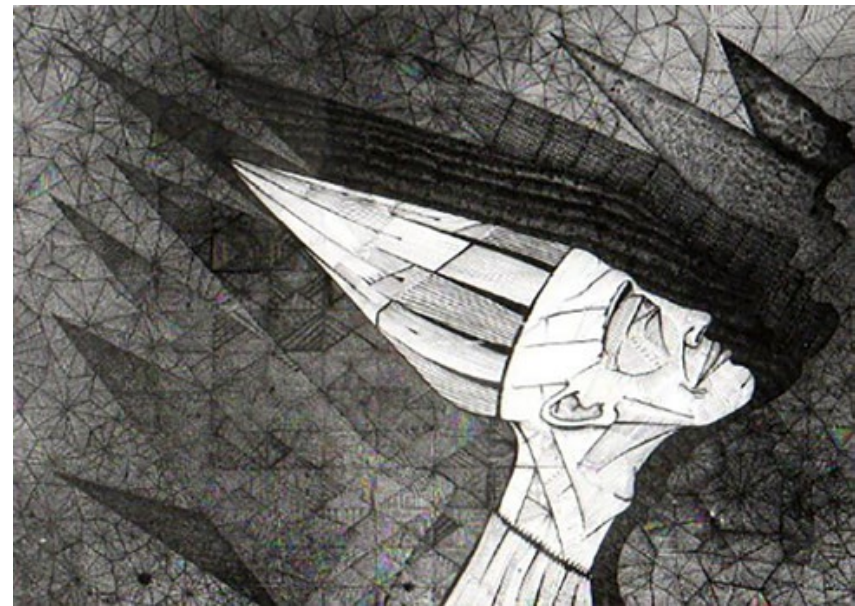

Figura 2: PONÇ, Joan. Suite Cabezas, São Paulo. 1958-1959.

Nanquim e guache sobre papel; 50,6 x $70 \mathrm{~cm}$. Fonte: Associació Joan Ponç, n. Catálogo 1627. Imagem disponível em: $<$ http://joanponc.cat/es/node/13418>.

5 MUSATTI, J. Entrevistas I, II e IV. Entrevistadora: Margareth dos Santos. São Paulo, janeiro, maio e outubro de 2017. 
Aliado a essas referências, encontra-se a identidade judaica assumida, como se comprova pela assinatura da obra (Figura 3):

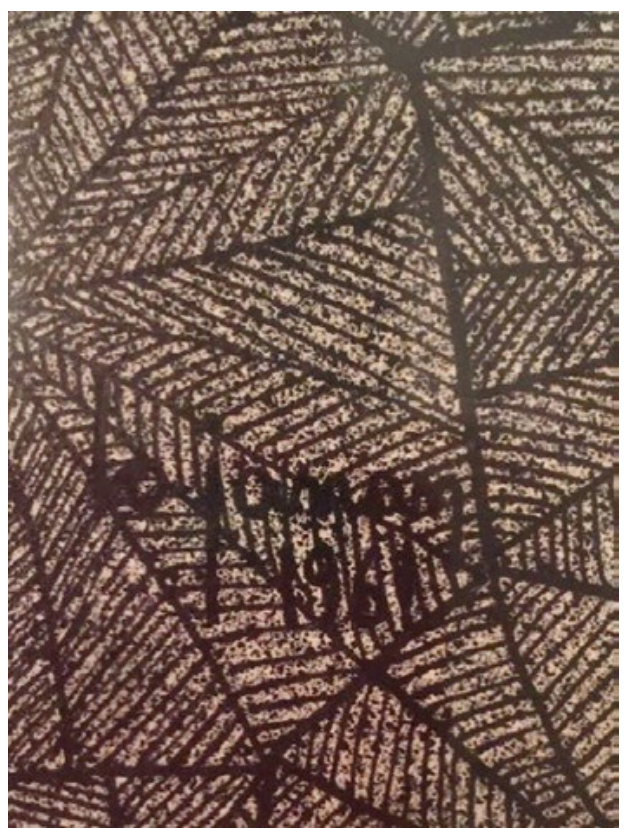

Figura 3: PONÇ, Joan. Detalhe da Suite Cabezas, São Paulo. 1958-1959. Nanquim e guache sobre papel; $50,6 \times 70 \mathrm{~cm}$. Fonte: Associación Joan Ponç, n. Catálogo 1627. Imagem disponível em: $<$ http://joanponc.cat/es/node/13418>.

Esse ato de assumir uma "nova identidade" criativa e comprometida com suas reflexóes sobre o mundo judaico no espaço brasileiro vai perdurar por alguns anos, inclusive em seu retorno à Espanha, como se pode comprovar pela correspondência (Figuras $4 \mathrm{e}$ 5) estabelecida entre Ponç e Jeanete ${ }^{6}$ :

6 De modo geral, toda a correspondência de Ponç nos anos imediatos ao seu retorno à Espanha está marcada por uma série de interferências do espanhol e do cataláo. Apesar de se poder considerar que o pintor escrevia razoavelmente bem em português, com construções complexas e o uso surpreendente de figuras de linguagem, essas interferências são frequentes e inevitáveis, devido ao contexto em que são escritas. 


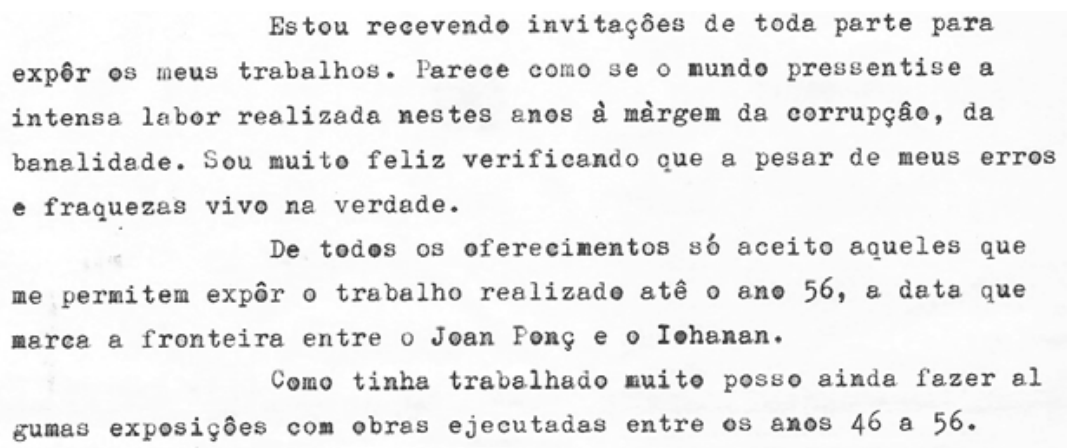

Figura 4: Fragmento da carta de Joan Ponç a Jeanete Musatti. Barcelona, 3 de março de 1965. Fonte: Arquivo pessoal de Jeanete Musatti (1965, p. 1).

Aquí na Bspanha, (sem esquecer da importância deste pais no mundo enteiro; ou seja a inumeravel gente que segue de perto as suas vicisitudes), na Espanha, digo, a opinião pública estava ja muito inclinada a me considerar o homem clave da minha geração, fal tando apenas um sucesso de ressonancia internacional. 0 grande premio conseguido em São Paulo, ha encaixado milagrosamente, como tudo na minha vida, dentro desta situação que me converte na figura do dia, (Deus queira que este dia dure muitos anos) do homem que representa a forçà que debe se opôr à corrupção. 0 mais importante crítico do país ha qualificado a minha obra como um drámático apêlo para retornar à seriedade.

Figura 5: Fragmento da carta de Joan Ponç a Jeanete Musatti. Barcelona, 18 de outubro de 1965. Fonte: Arquivo pessoal de Jeanete Musatti (1965, p. 1).

No entanto, ao retornar ao seu país e recusar-se a apresentar as obras do período brasileiro, a crítica catalá se vê desnorteada e náo compreende bem o porquê da ausência de obras desse período em sua primeira exposição na Espanha, realizada na Galería René Metras, em 1964:

$Y$ de repente un catálogo con una importante exposición suya ¿Sería posible? Sí. Joan Ponç ha vuelto a su tierra y vive en soledad en El Bruch, pero la exposición no es sobre la obra brasileña, sino de dibujos, grabados, monotipos, guachas y óleos de 1946 a 1953, es decir, de su producción antes de 
marchar al Brasil y que quedó en Barcelona en colecciones particulares. Nada inédito, en suma. Es el Joan Ponç de antes y no el de ahora, que nadie sabe cómo es, aunque en la muestra parezca adivinarse (CASTILLO, 1964, p. 115).

Ponç só começará a revelar à crítica e ao público espanhol as obras elaboradas no Brasil depois do êxito na VIII Bienal de São Paulo, quando ganha o prêmio na categoria de melhor desenho:

En la Sala René Metras se celebra una exposición homenaje a Juan Pons [sic], con motivo de haber sido galardonado con el I Premio de Dibujo de la Bienal de São Paulo.

Presenta dicho artista dos colecciones de obras, que pudiéramos señalar se encuentran relacionadas dentro de una misma linea temática. "Cabezas" y, un segundo grupo "clásicos".

Las "Cabezas" componen una carpeta que contiene 96 dibujos, de los que se exhiben tan sólo una parte. Podíamos decir que dos dibujos se van escalonando entre sí, existiendo una conexión entre unos y otros. Han sido realizados, según las fechas de ellas, en la etapa de 1959-61. El primero nos revela la cabeza de un hombre en estado primitivo, los instintos lo rigen; se encuentra aún en estado de naturaleza libre y salvaje. A partir de ahi, la serie de las "cabezas" (siempre de perfil, a la manera de los relieves egipcios) van tomando diversos aspectos, que las espiritualizan; o se abren, al modo surrealista, dejando asomar un pájaro a una paloma; o la rodea un espinoso y dramático ramaje; o se siente atraída por una serpiente (MANZANO, 1964, p. 7).

Embora não concordemos com a análise de Rafael Manzano, calcada no instinto e no primitivo, sem dúvida, há o virtuosismo de Ponç, que, em uma série de 99 cabeças que não se repetem, ainda que obedeçam a um mesmo gesto e movimento, no entanto, onde se vê a natura selvagem, vemos reflexão e compreensão, uma vez que o irrepetível se emparelha à experiência singular que pressupóem o convívio de Ponç com a cultura brasileira ${ }^{7}$ e judaica em solo nacional. Ademais, é compreensível que o pintor tenha guardado, de maneira

7 No artigo "Uma contenção diabólica" (no prelo), discuto o entrelaçamento da cultura judaica, do Candomblé e dos reisados brasileiros na Suite Cabezas. 
zelosa, essas obras, pois elas se firmaram como um divisor de águas em sua composição.

A correspondência de Ponç a Jeanete revela algumas questôes caras ao pintor: o desejo de ser reconhecido, aliado à sua negativa em relação ao mercantilismo de sua obra. Daí que o grande prêmio da Bienal, de fato, tenha caído como uma luva, pois assinala seu reconhecimento em âmbito internacional como artista e homem, numa simbiose entre estética e ética, sustentada a ferro e fogo por Ponç durante sua carreira.

Não obstante, essa resistência ao mercantilismo nem sempre foi possível, uma vez que Ponç teve que produzir muito em papel para sustentar-se no Brasil. Entre esses sacrifícios, em prol de uma vida razoavelmente digna, esteve a venda maior parte da Suite Cabezas, o que ocasionou a dispersáo de sua unidade e sentido dos dois lados do Atlântico, uma vez que caiu em máos de colecionadores particulares:

Inicio la suite Instrumentos de tortura, cuarenta acuarelas que sufren un proceso de destrucción, la última de ellas es un papel prácticamente rasgado. Inmediatamente después seguirá la suite Pájaros, y más tarde la suite Cabezas, compuesta de noventa y nueve acuarelas. Siempre me culparé de haber vendido esta suite, que ha sido dispersada, cuando debia haber permanecido unida para tener todo su sentido (PONÇ, 2009, p. 165).

Náo cabe dúvida de que "todo sentido" da série a que se refere Ponç está ligada às suas incursôes pela cultura e folclore brasileiros e pelo estudo do judaísmo em terras nacionais. A fusão desses elementos se verá cristalizada, sobretudo, na Suite Cabezas, em que coexistem a busca por um sentido da vida e do homem no mundo e por meio dessa procura advêm, necessariamente, preocupaçóes de fundo místico, essencial na obra e na vida do pintor cataláo.

A absorção desses elementos revela, igualmente, o mergulho de Ponç na cultura brasileira aliada à sua leitura do cotidiano, da reflexão sobre seus ritos e de seu folclore -cujas raízes nos remetem à Península Ibérica - e, por fim, da convivência de distintas religióes, lidas através do conjunto das 99 cabezas poncianas. 
Ademais desses elementos, imbricados em distintos planos, as séries confluem em outra esfera: o método de composição que Ponç passaria a cultivar fortemente no Brasil, concebido no desenho preparatório em pequenas proporçóes.

A veces, las cosas están en mi mente, como escritas en pequeños papeles, que colgados de hilos de diferentes dimensiones, se mueven estremecidos por un extraño y obscuro viento. Otras veces, están firmes, seguras de si mismas, salen al exterior, ordenadamente, como los paracaidistas se lanzan al vacio desde sus aviones (PONÇ, 2009, p. 165).

O exercício milimétrico e mínimo dos croquis em três séries poncianas - Instrumentos de tortura, Cabezas e Pájaros (Ocells) -, manifestam um método movido pela reflexão detida e pela inspiração intempestiva, misturadas, elas expóem uma criação quase ininterrupta, que pode brotar desde a observaçáo contínua e prolongada da natureza, até a necessidade de sincronizar o visto com o imaginado (Figuras 6, 7 e 8).
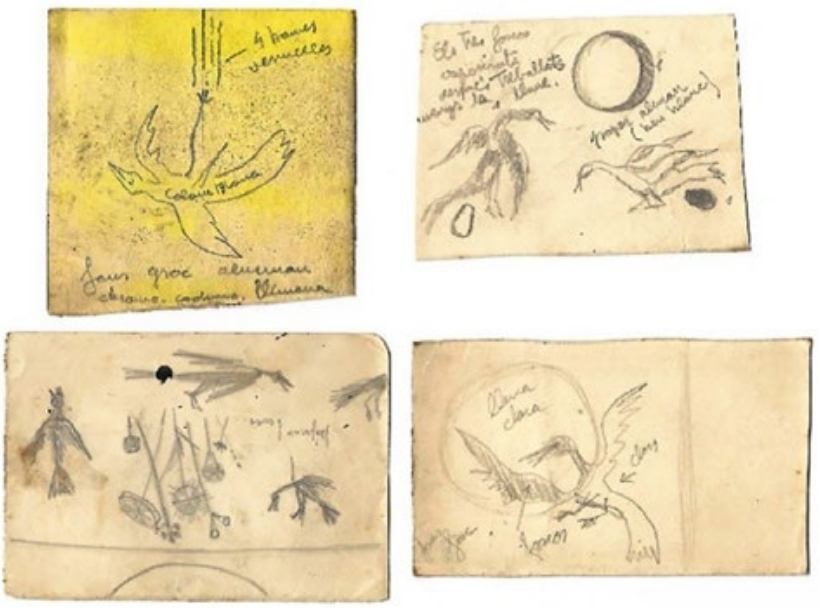

Figura 6: PONÇ, Joan. Croquis da Suite Pájaros. 1958-1961. Lápis e tinta sobre papel. $6 \mathrm{~cm} \mathrm{x} 4 \mathrm{~cm}$. Fonte: Acervo Família Rabinovich. 

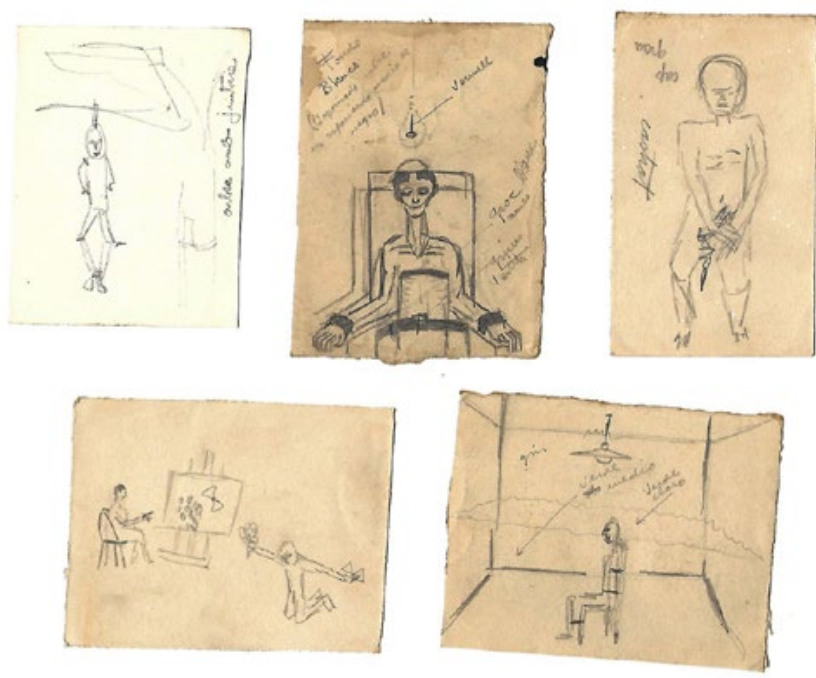

Figura 7: PONÇ, Joan. Croquis da Suite Instrumentos de tortura, 1956. Lápis e tinta sobre papel. $6 \mathrm{~cm} \mathrm{x} 4 \mathrm{~cm}$. Fonte: Acervo Família Rabinovich.

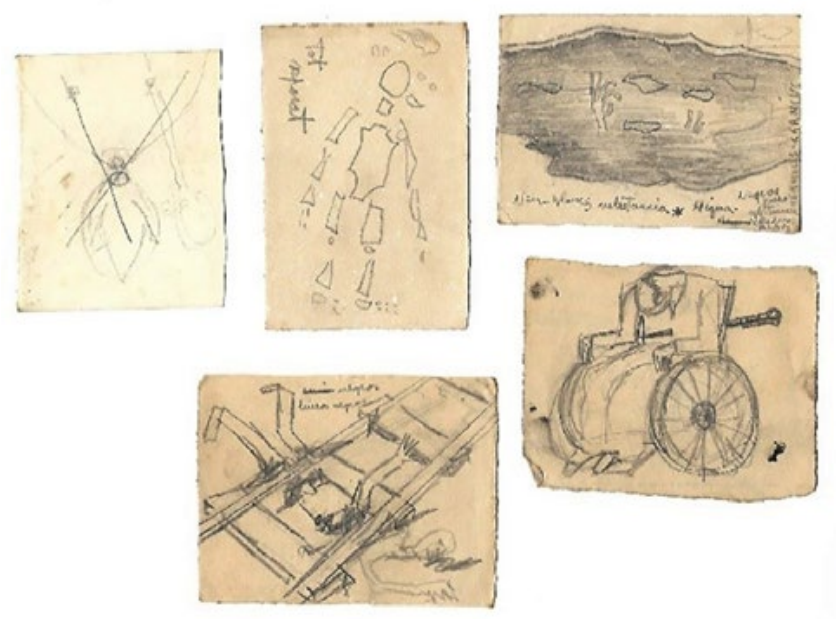

Figura 8: PONÇ, Joan. Croquis de seres torturados e fragmentados, 1956-1957. Lápis e tinta sobre papel. $6 \mathrm{~cm} \mathrm{x} 4 \mathrm{~cm}$. Fonte: Acervo Família Rabinovich. 
Daí que os diminutos croquis tenham sido gestados em distintos tempos e espaços: no interior do ateliê de Ponç, em seus passeios por Ribeirão Pires e por São Paulo.

Essa prática, entre a captura da paisagem fugaz, a preocupação pela cor e pela forma, o desenho preciso e em filigrana perdura também na volta de Ponç à Espanha e está representada, sobretudo, pela Suite Caps secrets (Caixas secretas), pequenos desenhos que o artista compóe na sala de espera do hospital em que tratará as sequelas da diabetes que se manifestou em seu período no Brasil.

Por fim, vale a pena destacar que nos croquis de suas séries manifesta-se uma preocupação estética e teórica que surge em boa parte da obra do pintor cataláo: a fragmentação do corpo. Um exemplo dessa inquietação são os desenhos acima e os que seguem abaixo (Figura 9), que nos mostram um corpo fraturado, em que a legenda "tot separat" (tudo separado) dá o tom da série, em que corpos aparecem torturados ou em partes: são mãos, pés e cabeças isoladas, violentas e apavoradas:
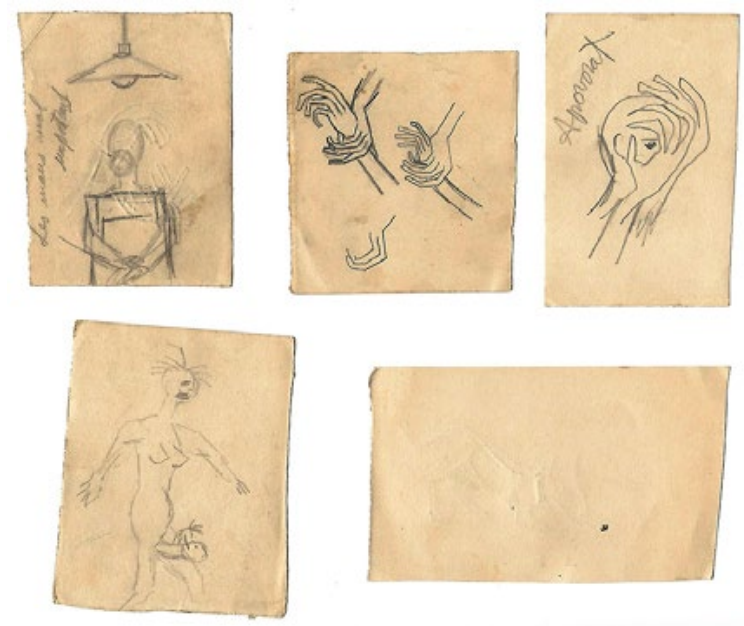

Figura 9: PONÇ, Joan. Croquis de seres torturados e fragmentados, 1957. Lápis e tinta sobre papel. $6 \mathrm{~cm} \mathrm{x} 4 \mathrm{~cm}$. Fonte: Acervo Família Rabinovich.

A partir desses seres despedaçados vislumbramos uma relação entre a obra que Joan Ponç produziu no Brasil - e mais tarde, em 
sua volta à Espanha - e as reverberaçóes do convívio com seus alunos e amigos próximos: o cinema.

\section{Uma estética do estilhaço}

Em todas as entrevistas de seus ex-alunos e com seus irmãos, sem exceção, eles apontaram para a paixão de Ponç pelo cinema. Assíduo frequentador das salas paulistas, o pintor teve uma especial predileção pelas salas do bairro da Liberdade, às quais acudia a pé e quase sempre na companhia de alguns de seus alunos ou amigos.

Naquela época, a Liberdade era considerada uma espécie de bairro outsider, frequentado, sobretudo, pela colônia japonesa e seus descendentes, mas que teve um período de vivo interesse por sua cultura, em parte, graças aos cinemas que recuperaram elementos importantes do universo oriental através das exibições de filmes históricos, de samurais e de filmes intimistas, conhecidos como a "novelle vague" japonesa:

Com as inauguraçóes do cine Niterói em 1953 e do cine Tóquio em 1954, a perspectiva era de que a grande produção anual de filmes japoneses afinal chegasse a São Paulo. Mas não foi isso que aconteceu. A média de filmes até 1957 foi de 35 filmes por ano. A situação só mudou com a vinda da Toho Filmes, em 1958, para lançar suas produçôes no cine Tóquio. E no ano seguinte, 1959, tivemos mais três fatos auspiciosos: a abertura do escritório da Shochiku Filmes, a inauguração do cine Nipon, da Nippon Filmes local, e a transformaçáo do cine Jóia em exibidor exclusivo dos filmes da Toho, que alugou o cinema. Com a passagem do cine Niterói a lançador exclusivo da Toei Filmes, em 1961, e a reabertura, em 1962, do antigo cine Tóquio, agora com o nome de cine Nikkatsu, para exibição das produçóes dessa companhia, São Paulo passava a ter quatro cinemas japoneses, tornando-se o período 58-62 a fase de outro do cinema japonês em São Paulo (RODRIGUES, 1995, p. 166).

Nessas salas imperava o cinema japonês, com especial destaque para a série de filmes sobre o samurai conhecido como Miyamoto Musashi. Deslumbrado pela estética da violência do cinema japonês, 
seu ritmo narrativo e pelo tratamento dado a questôes existenciais a partir do cotidiano, Ponç frequentou o cine Joia e o cine Niterói na companhia de Moisés Baumstein, Moacyr Rocha e Paulina Rabinovich, que recorda essa etapa da amizade de ambos nos anos 1960:

As trocas que tínhamos eram em nível de pintura e em nível espiritual, as ideias dele estavam dentro de conceitos espirituais, o budismo, que era o budismo japonês, ele tinha o conceito da estética do budismo japonês, da ação do budismo, no sentido do domínio do homem. Ele trazia muito isso, como íamos diariamente ver os filmes do Miyamoto Musashi na Liberdade, o que a gente ia ver no Miyamoto? A capacidade dele do domínio da espada e fora o domínio da espada, como ele dominava as cinco artes. Qual era o ensinamento do Miyamoto Musashi? Como eram as cinco rodas? (RABINOVICH, 2017).

Vale a pena notar que a preocupação de Ponç pelos conceitos levantados por Paulina Rabinovich coincidem, em grande parte, com os relatos de outros frequentadores das salas de cinema do bairro da Liberdade, posto que muitos dos espectadores dos filmes japoneses naquela época relacionam os filmes de Musashi à uma ideia de ascese e hieratismo, segundo o que pôde comprovar Alexandre Kishimoto em sua entrevista ao crítico de cinema Cláudio Willer:

Vamos voltar ao Miyamoto Musashi, tanto o de Inagaki quanto o de Uchida. É claro que é idealização, mas a vida dele é apresentada como uma ascese, como uma espécie de elevação búdica. Nos dois filmes mostra-se o aprimoramento, ele também fazendo o ukiyo-e, desenvolvendo-se artisticamente, então [há] essa ideia de ascese, de transformação interior. E o interessante é o modo como isso é trazido para a tela, diferente do desenvolvimento de um western, em que o foco recai numa luta entre o bem e o mal, e não numa filosofia (WILLER apud KISHIMOTO, 2009, p. 89).

Na entrevista concedida em 2017, a pintora Paulina Rabinovich também se refere à destreza do lendário samurai japonês e ao Livro dos cinco anéis (Go Rin No Sho), escrito por Musashi no final de sua vida. $\mathrm{O}$ volume em questáo recolhe os ensinamentos 
do espadachim sobre estratégia, aplicada como um caminho para o aperfeiçoamento de qualquer ser humano que queira conhecer a si mesmo e evoluir:

Nascido em 1584, Miyamoto Musashi estava destinado a se tornar um dos mais famosos guerreiros do Japáo. Musashi foi um samurai e, com 30 anos de idade, já participara de mais de 60 combates, vencendo a todos e matando seus adversários um a um. Certo de sua invencibilidade, Musashi resolveu deixar registrada a sua filosofia, "o Caminho da Espada". Para isso, escreveu o livro ao qual denominou O Livro de Cinco Anéis (Go Rin No Sho enquanto residiu numa caverna das montanhas de Kyushu, poucas semanas antes de sua morte, em 1645.

O Livro de Cinco Anéis é imprescindível em toda bibliografia de artes marciais; porém a filosofia que o rege, influenciada pelo Zen, pelo Xintoísmo e pelo Confucionismo, pode ser aplicada a diversos outros setores da vida além das artes marciais [...]

Musashi é conhecido pelos japoneses como Kensei, ou "santo da espada". Embora sua vida possa dar aos ocidentais a impressáo de um homem cruel e impiedoso, Musashi esforçou-se inabalavelmente por atingir um ideal honesto, cuja verdade é transparente em $O$ Livro de Cinco Anéis. Seu livro não apresenta uma tese sobre estratégias de luta e sim, nas suas próprias palavras, "uma orientação para os homens que desejam aprender estratégia (MUSASHI, 1984, p. 12).

A série de cinco filmes dedicados a Miyamoto Musashi foi lançada em São Paulo pela Toei, uma importante distribuidora de filmes japoneses no Brasil. Os cinco filmes dirigidos por Tomu Uchida, exibidos no Cine Niterói entre os anos 1961 e 1966, integraram uma época áurea do cinema japonês na capital paulista e representou um dos maiores êxitos dessa sala de exibição.

A sequência exibida pelo cine Niterói angariou inúmeros adeptos, descendentes e náo descendentes de japoneses, como os cineastas Carlos Reinchenbach, Rogério Sganzerla, Walter Hugo 
Khouri e o professor de Sociologia da USP Sedi Hirano ${ }^{8}$. Alguns valorizavam a questão estética da série, outros, os valores espirituais e culturais, mas todos concordavam com a ideia de que essa filmografia representou um marco para o cinema nos idos dos anos 1960:

De Uchida ainda tivemos outros grandes filmes, como Tragédia em Yoshiwara, História de um Amor em Naniwa, Estranho Amor, e principalmente, Miyamoto Musashi, em cinco épocas, em que o famoso espadachim sempre indagando a causa dos duelos e o sensabor de suas vitórias; procurando aperfeiçoar-se espiritualmente e sempre insatisfeito, empenhado numa incessante busca existência de valores. Mas, ao final, sem encontrar senão a incerteza, Musashi, após mais uma memorável vitória, parte amargurado, mas em busca de desafio - sabendo da inutilidade do esforço, mas o fazendo sempre num ato de revolta, num surdo rilhar de dentes contra o destino, numa afirmação de luta: o único valor possível do homem (RODRIGUES, 1995, p. 168).

O apanhado de José Fioroni Rodrigues aponta para dois elementos caros a Ponç: o estético e o espiritual. E estes convergem para algo intensamente perseguido pelo pintor catalão, o aperfeiçoamento. Tanto em seus escritos como em suas declaraçóes, Ponç assinala uma busca por um sentido de sua existência, que só a pintura e a escritura são capazes de dar:

29-VI-60

Campanas, tempo-sonido, dan las ocho de la noche. Hoy no pude pintar, tengo trabajado intensamente y siéntome agotado. Escribo para permanecer, por esta increible necesidad de materializar la existencia. ¿Para qué? El náufrago se agarra a cualquier cosa. Esta caligrafía me sostiene débilmente. El movimiento de la mano del que surgen estas letras sobre el papel de nieve es tan necesario como que pueda decir. A

8 Alexandre Kishimoto, em sua notável dissertação de mestrado intitulada $A$ experiência do cinema japonês no bairro da Liberdade, realizou uma série de entrevistas com os personagens ora citados sobre suas experiências com o cinema japonês em São Paulo. Ao longo desse apartado, citaremos alguns trechos dessas entrevistas a fim de contextualizar e corroborar nossa pesquisa. À dissertação também devemos uma parte da bibliografia aqui utilizada nas referências ao cinema japonês e sua reverberação nos anos 1960 . 
través de la escritura, fisica y espiritual al mismo tiempo, el alma flota y el cuerpo respira, y mira las estrellas, y abro la boca lo más posible para absorber la máxima cantidad de aire posible ¿Para qué? ¿No sería mejor sumergir? No, no me es posible. Por miedo o por coraje, no me es posible (PONÇ, 2009, p. 48).

Em sua escritura, a pintura e a reflexão surgem como vetores que guiam o pintor em seu labor. Nela, o movimento da mão é capaz de criar seres torturados e fragmentados que retomam, de certa forma, a estética e a ética da violência dos filmes japoneses vistos diariamente, como uma educaçáo pelo olhar que observa os movimentos precisos do samurai lendário. A incorporação desse universo japonês também se imiscui em suas telas através do exercício vanguardista da collage:

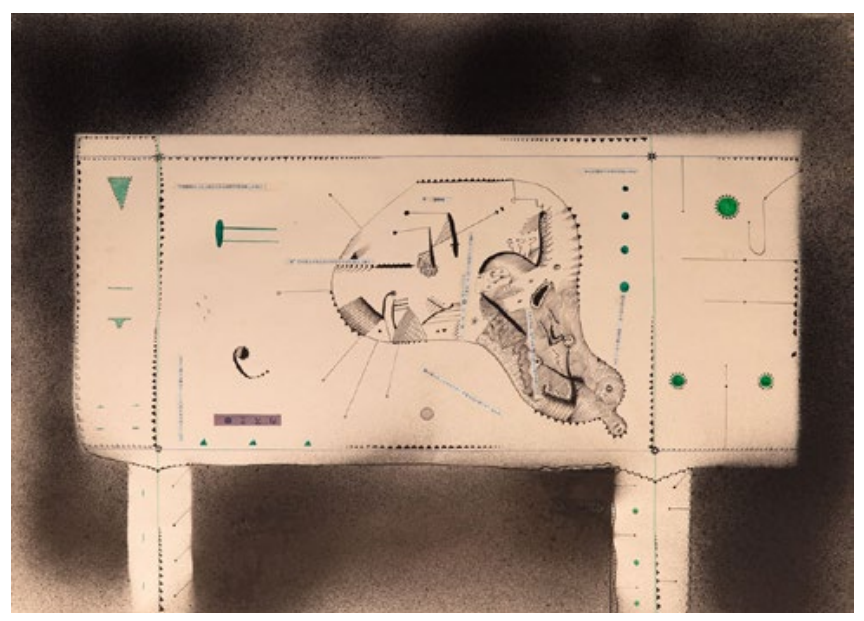

Figura 10: PONÇ, Joan. Suite mesas, no 41, 1960. Nanquim, tinta sobre papel e collage. $70 \mathrm{~cm}$ x $50 \mathrm{~cm}$. Fonte: Acervo Galería Senda.

Se nos croquis víamos seres mutilados com precisão, na Suite mesas - cuja imagem evoca a tela de um cinema por seus contornos e luzes - temos uma imagem em que a técnica nos lembra um recurso daliniano: a construção de uma imagem dentro da outra, captada a partir da aproximação ou do distanciamento do espectador.

No desenho de Ponç (Figura 10), se observarmos a imagem de longe, ela nos parece um elemento disforme, cercado por colagens 
de ideogramas japoneses. Estes ideogramas estáo constituídos por fragmentos de livros de botânica, que se referem a dois tipos de flores: a branca, que resiste ao inverno e, por isso, possui maior força; e a vermelha, que apesar de sua beleza, é frágil e não sobrevive à estação mais fria do ano. Portanto, através de cacos textuais, discute-se a ideia de força conjugada à de natureza.

Mas, se observarmos os detalhes da figura de perto, percebemos um mapa que se assemelha a um arrozal e em seu interior os ideogramas japoneses se incorporam à forma da figura:

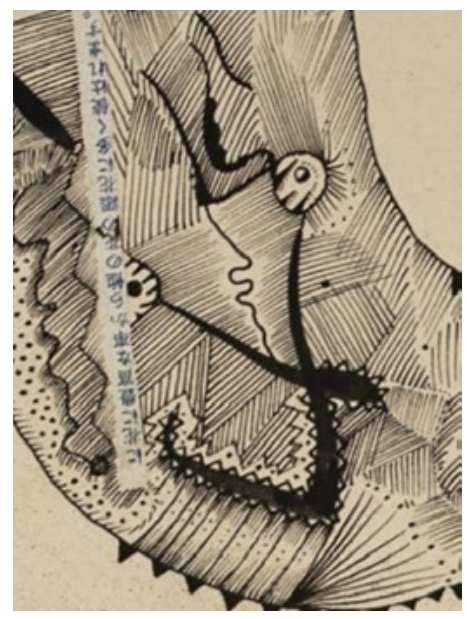

Figura 11: PONÇ, Joan. Detalhe Suite mesas, no 41, 1960.

Nanquim, tinta sobre papel e collage. $70 \mathrm{~cm}$ x $50 \mathrm{~cm}$. Fonte: Acervo Galería Senda.

O ideograma isolado e incorporado à imagem significa "força", ou seja, Ponç estabelece nesse desenho um duplo jogo entre imagem e significado, ao mesmo tempo em que remete aos ensinamentos do espadachim Musashi, em que a força e a precisão conjugavam-se de maneira única (Figura 11).

Essa percepção de força e precisão, como algo próprio da arte e da açáo orientais, também se repetiria na experiência do professor de história oriental, Ricardo Gonçalves ao assistir aos filmes sobre Musashi, tal qual ele relata em entrevista concedida a Kishimoto: 
Você se identificar com os personagens, por exemplo, quem adorava filmes de samurai, identificar-se com o Musashi é uma experiência forte. [...] O filme que me marcou muito mesmo naquela época foi a série Miyamoto Musashi, do Tomu Uchida. A percepçáo que eu tinha é que aqueles filmes conseguiam transmitir alguma coisa de fundamental a respeito do alicerce espiritual da cultura japonesa. Em grande parte, estes filmes me motivaram muito a caminhar em direção ao budismo (GONÇALVES apud KISHIMOTO, 2009, p. 89).

A recorrência de comentários sobre o interesse pelo budismo e a absorção de bases espirituais da cultura japonesa, além de uma admiraçáo genuína sobre a estética, o ritmo, o movimento dos filmes japoneses e seus personagens atestam, de certa forma, um grande alcance desse universo oriental sobre os frequentadores que não eram descendentes de japoneses, mas que viam naquelas exibiçóes uma nova maneira de enxergar e exercer a arte e suas próprias vidas:

Assistia maravilhado, como se o próprio Japão fosse um cenário, onde aquelas histórias e aquelas pessoas fossem paralelas às aventuras das Mil e Uma Noites. Sabor trágico, dramático, os rostos e posturas imóveis, de sentido enigmático, fatal. E os filmes de samurais, então?...

Terríveis, cruéis, profundos nas suas dobraduras. A expressão artística asiática, principalmente a japonesa, sempre me envolveu numa aura mágica, de aventuras quase transcendentais. Cheguei ao topo, como se sabe, com Kazuo Ohno. Esses impactos de emoção e sensações sempre procuro imprimir nos meus espetáculos - a arte tem que transportar, fazer perder o chāo! (FILHO, 2011, p. 1)

A possibilidade de fazer perder o chão, ou seja, de ser surpreendido por meio de emoçóes e sensaçóes inesperadas e inusitadas se embaralham no exercício de contenção e apropriação de Ponç dos elementos da paisagem, da cultura e da arte brasileiras, traduzidas não apenas em sua obra, mas em sua inesgotável capacidade de absorção por meio do convívio e do estudo, refletida também em seus escritos e em seu diário, entendido como um lócus de reflexão, em que se 
materializam seus enfrentamentos com o entorno, com sua obra e consigo mesmo.

Configurado a partir de uma natureza híbrida, entre o mundo dos outros e o mundo do eu, o diário de Ponç em terras brasileiras, ao qual recorremos em distintos momentos nesse artigo, revela-se como um território de pequenas epifanias, em que convivem a expressão do eu em distintos níveis:

Mais les écritures du moi ne forment pas de filières indépendantes les unes des autres; les diverses expressions de la première personne communiquent entre elles à la source, témoignages d'une même anthropologie culturelle; la conscience de soi s'ouvre des voies afin de parvenir d'une manière ou d'une autre au jour de l'incarnation écrite. (GUSDORF, 1991, p. 239).

Essas pequenas iluminaçóes, encarnadas na escritura íntima, possibilitam ao pintor traçar parte de sua história no Brasil. Ainda que de maneira fragmentada e salpicada por metáforas, essa escritura recompóe uma individualidade colada a uma coletividade, unidas pela recuperaçáo de um passado reordenado e recriado por uma mão que pinta e escreve a fim de revelar uma extrema inquietude do ser, e esta se fixa entre o real e o imaginário.

J'écris, donc je suis. Jécris, donc j'ai été; jécris, donc je serai. L'écriture consolide cette ombre que je suis, elle lui assure une consistance, une permanence, en dépit de l'écoulement du temps. Je me raconte à moi-même la légende de ma vie, ma part du monde, ma part de vérité, non pas de vérité selon le monde, mais de vérité selon moi. Parcours de songe, substitué à l'histoire de la vie. Mythistoire. (GUSDORF, 1991, p. 490).

Para quem viveu com "o pincel na mão" - desviando a expressão com que Georges Gusdorf descreve Pascal (GUSDORF, 1991, p. 286) - não é demais afirmar que "pintar era a vida" e o ato de escrever não se converteu em um reflexo secundário, numa mera transcrição da vida, mas em uma "[...] transcription de la vie elle-même, le sens de l'existance" (GUSDORF, 1991, p. 157). 
Portanto, podemos arriscar dizer que os atos de ver, pintar e escrever acompanharam a vida de Ponç no Brasil (e, posteriormente, na Catalunha) e essas açóes se constituíram como intervençóes que agiram em prol do conhecimento de si, atuando enquanto elementos mediadores de que Ponç dispôs e lançou mão para consagrar o que viveu e refletiu.

Claro está que nenhuma dessas dinâmicas funcionaram como decalque, mas sim como um gesto que configurou-se como "[...] le signe du malaise existentiel dont il souffre, et le premier mouvement d'une rupture de conformite"' (GUSDORF, 1999, p. 170).

Assim, podemos terminar esse texto afirmando que escrever e pintar converteram-se em distintas caligrafias, sempre marcadas por uma insaciável curiosidade pelo outro, plasmado em cultura, religiáo, rito e paisagem. Misturados, esses elementos puderam nos proporcionar o percurso de Joan Ponç no Brasil, em que arte e escritura se embrenharam num movimento entre o vivido e o pintado.

\section{Referências bibliográficas}

CASTILLO YURRITA, A. del. Crónica de Barcelona. Goya: Revista de arte. Madrid: Fundación Lázaro Galdiano, set.-oct., 1964, n. 62, p. 115119.

FILHO, A. Sensaçôes do Japão. Sesc-São Paulo, 10/08/2011. Disponível em: <https://www.sescsp.org.br/online/artigo/compartilhar/5475_ LIBERDADE+CINEMATOGRAFICA $>$. Acesso em 11 de junho de 2018.

GUSDORF, G. Lignes de vie 1. Les écritures du moi. Paris: Éditions Odile Jacob, 1991.

MUSATTI, J. Entrevistas I, II e IV. [janeiro, maio e outubro. 2017]. Entrevistadora: Margareth dos Santos. São Paulo, janeiro, maio e outubro de 2017.

KISHIMOTO, A. A experiência do cinema japonês no bairro da Liberdade. 2009. Dissertação de mestrado. São Paulo, USP/FFLCH, 2009.

LEIRNER, N. Entrevista III. [jul. 2017]. Entrevistadora: Margareth dos Santos. Rio de Janeiro, julho de 2017. 
MANZANO, R. Homenaje a Juan Pons y exposición de 'grafistas'. Thorne y mundo lírico. Soliridad Nacional. Diario Sindicalista de Cataluña. Secció Arte. Barcelona, 24 de setembre de 1964, p. 7.

MUSASHI, M. O livro de cinco anéis. Rio de Janeiro: Ediouro, 1984.

PONÇ, J. Croquis da Suite Instrumentos de tortura, 1956. Acervo Família Rabinovich.

. Croquis de seres torturados e fragmentados, 1956-1957. Acervo Família Rabinovich.

- Croquis de seres torturados e fragmentados, 1957. Acervo Família Rabinovich.

. Suite Cabezas, Sáo Paulo. 1958-1959. Associació Joan Ponç, Barcelona. (n. catálogo 1627). Disponível em: <http://joanponc.cat/es/ node/13418>.

. Croquis da Suite Pájaros. 1958-1961. Acervo Família Rabinovich.

. Suite mesas, n. 41, 1960. Acervo Galería Senda.

- Carta de Joan Ponç a Jeanete Musatti. Barcelona, 3 de março de 1965. Arquivo pessoal de Jeanete Musatti, 1965a, p. 1.

. Carta de Joan Ponç a Jeanete Musatti. Barcelona, 18 de outubro de 1965. Arquivo pessoal de Jeanete Musatti, 1965b, p. 1.

. Diari d'artista i altres escrits. Barcelona: Edicions Poncianes, 2009.

RICOUER, P. A memória, a história, o esquecimento. Editora Unicamp: Campinas, 2000.

RODRIGUES, J. F. Panorama do cinema japonês e sua época de ouro. Revista da USP. São Paulo: CCS-USP, 1995, no 27. Dossiê Brasil-Japão, p. 165-169.

Margareth dos Santos. Doutora em Literatura Espanhola pela USP, professora do Departamento de Letras Modernas da Universidade de São Paulo (USP). Suas linhas de pesquisa compreendem o exame das relaçôes entre literatura, história e arte no século XX, tanto na Espanha como no contexto ibero-americano na produção vinculada à Guerra Civil Espanhola e ao pós-guerra civil espanhola. Autora da obra Desastres do Pós-guerra Civil Espanhola e organizadora do dossiê "80 anos da Guerra Civil Espanhola: leituras e releituras", na Revista Caracol. Atualmente desenvolve o projeto Joan Ponç e o Brasil: pintura e literatura em movimento em que discute relaçóes entre arte e literatura. E-mail: marsanto@usp.br

Recebido em: 15/09/2018

Aceito em: 20/12/2018 